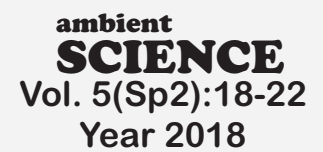

\title{
Seed Germination and the Respective Enzyme Activities in it: a Case Study of Tamarindus indica $\mathrm{L}$.
}

\author{
Sweta Gaikwad *, Kavita Sharma \\ Department of Botany, Govt. Arts and commerce Girls'College, \\ Devendra Nagar, Raipur.- 492009, India \\ Study Area: Raipur, Chhattisgarh, India \\ Coordinates: $21.25^{\circ} \mathrm{N} ; 81.63^{\circ} \mathrm{E}$
}

Key words: Legume seeds, Amylase, Protease, Lipase, Cotyledons

\begin{abstract}
Seeds of tamarind (Tamarindus indica L.) is widely distributed but highly neglected. In spite of its having high nutritious value, commercialization of it is not yet taken seriously. One of the major reasons could be their poor germination rate. In the present study, the extraction and estimation of three major hydrolases, Amylase, Protease, and Lipase were done at all the six important intermediate phases of germination. The percentage of hydrolases were found to vary at different phases of germinations. More starch was degraded during early phases of germination. Initial phases showed rapid protein degradation. Protein mobilization into the axis lowered its level in cotyledons due to in situ utilization of soluble protein and reduction of nitrates into plant proteins. Lipase activity was higher during initial phases due to more availability of water for stored lipid hydrolysis. These facts would be helpful in developing new technologies to improve germination percentage of tamarind and other similar seeds.
\end{abstract}

Mobilization happens because of enzymes which digest the large molecules. So enzymes are large biological molecules responsible for the thousands of chemical inter-conversions that sustain life. Just like other seeds obviously, the seeds of Tamarind indica L. also utilize the stored food materials at various stage of seedling growth and development. In the present study, an attempt to analyze the rate of 3 major hydrolases with respect to all the important phases of germination for this particular seedling has been taken.

\section{Methodology:}

Tamarindus indica $\mathrm{L}$. is a leguminous tree found throughout the country. Most of the parts of the tree like barks, leaves, fruits, seeds, and roots of the trees are used for pharmaceutical raw materials, food and fodder. The seeds yield jellose which is used for sizing jute and cotton. The poyose also obtained from the seeds, is a good substitute for food pectins. The starch and some other valuable nutrients could also be extracted from its seed for various uses. The unripe fruits are good source of tartaric acid which is extensively used in various foods, chemicals, and pharmaceutical industries.

As the first step of our study the germination ability of the tamarind seeds under different conditions and then extraction and estimation of the major hydrolases the molecules in to something useful to the plant.

*Corresponding Author: swetagaikwad7@gmail.com 
(amylase, protease, and lipase), were executed. All the important intermediate phases of epigeal germination through the following described steps:

The tamarind seeds were obtained by collecting the fruits by soaking in water overnight, air dried for more than $6 \mathrm{hr}$ Damaged seeds were sorted from the good ones. The selected healthy seeds of uniform size were germinated following Misra \& $\operatorname{Kar}$ (2002).

Six most important phases of germination were considered as:

"I"- Phase of Imbibition (attained after 24 hr of imbibition in water).

"R"- Phase of Radicle expansion (attained after 96hr of germination).

"H"- Phase of Hypocotyl extension (attained after 144hr of germination).

"B"- Phase of Branching in radicle (attained after $216 \mathrm{hr}$ of germination).

"E"- Phase of Epicotyl extension (attained after $264 \mathrm{hr}$ of germination).

"L"- Phase of unfolding of first Leaves (attained after 312hr of germination).

In order to determine the germination ability of tamarind seeds, three different procedures were simultaneously performed; i). 100 seeds stored in poly bags at room temperature, ii) 100 stored at $15^{\circ} \mathrm{C}$ and iii) 100 imbibed seeds ( $24 \mathrm{hr}$ in water) were taken and germinated by following the process of Schmidt (2000). The processes were repeated for several times to get four replicates of each type.

All the 4 sets of single tamarind seed were taken in petriplates separately at phase "I" (Phase of imbibition) i.e. after $24 \mathrm{hr}$ of imbibition. Their seed coats were removed to get a pair of cotyledons. Each seed was found to be of 8oomg which were analyzed for their enzymatic activities during the process of germination, considering Amylases, Proteases, and Lipases separately. The biochemical estimations were done with four replicates and the average values were calculated with respect to the total weight of a pair of cotyledons of the Tamarind seeds.

The estimation of amylase activity in the germinating cotyledons was done by using DNS-reagent method by following Plummer (2011) as followed by Oboh (2005).

Protease activity in the germinating cotyledons of tamarind was estimated by using azocasein as a standard by following the method of Nigam \& Ayyagari, (2007) as followed by Arunachalam \& Saritha (2009).

Lipase activity in germinating cotyledons of tamarind was estimated by using the prescribed method by Nigam \& Ayyagari (2007) also followed by Nahak et al. (2010).

\section{Results :}

All the above extraction and estimation were done at all the six intermediate phases taken under consideration separately. Germination ability of seeds stored and germinated under different conditions revealed the following results i) Total $18 \%$ germination was exhibited by the seeds stored in poly bags at room temperature,

Seeds stored at $15^{\circ} \mathrm{C}$ revealed $63 \%$ of germination and iii) Seeds imbibed for $24 \mathrm{hrs}$ in normal tap water showed $60 \%$ of germination.

During the experiment, the values for amylase activity (units/pair of cotyledons) of Tamarindus indica L. seeds ranged from 345 to 469 (From first phase "I" to the last phase "L") during the process of germination. The Amylase activity increased up to the phase "E" (Phase of epicotyl extension) in germinating cotyledons. TheThe maximum value and the minimum value were recorded at phases "E" and "I" respectively. ANOVA result revealed significant differences among all the phases of activities. Except the pahses "B" and "L" rest all the pahses were Statistically diffe零ed from each other

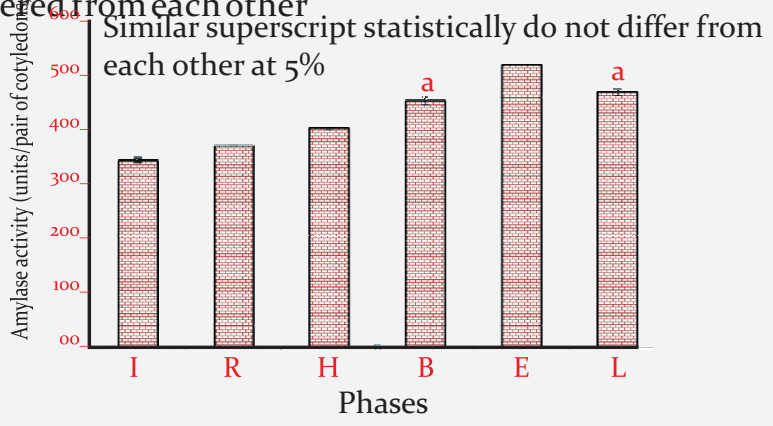

Figure-1: Amylase activities of Tamarindus indica L. seeds during the different phases of germination

An increase of protease activity was noticed when the seed went through the initial phase of germination that is change from phase "I" to "B". Suddenly the rate of protease activity decreased during the the phase "B" to "L". This decrease in the rate of activity was calculated $50 \%$ and thus phase "B" was considered to be the peak point of the enzyme action after which the rate was decreased. ANOVA result revealed significant differences among all the phases of activities. Except the pahses "I" and "E" rest all

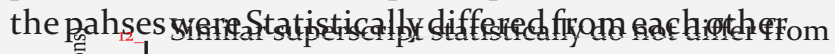

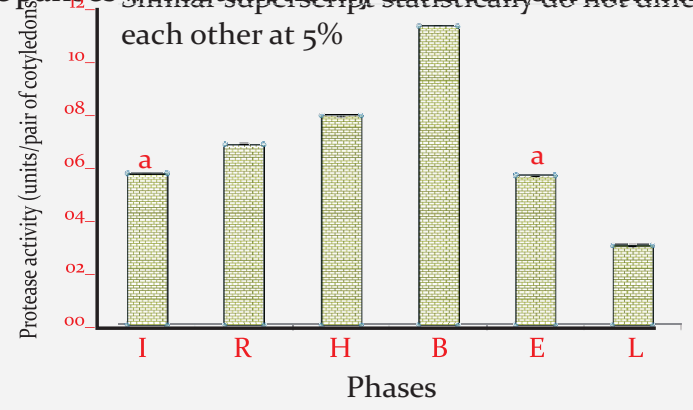

Figure-2: Protease activities of Tamarindus indica L. seeds during the different phases of germination

An increase in Lipase activity was highest during the 


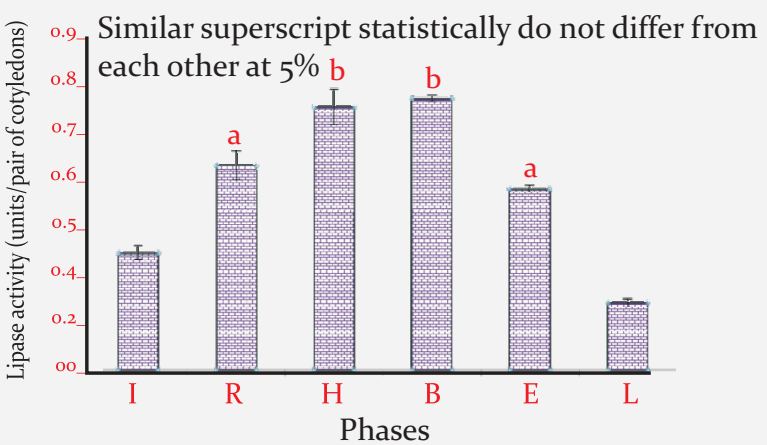

Figure-3: Lipase activities of Tamarindus indica L. seeds during the different phases of germination

phase "B" and then a rate of enzyme action was slowed down. In the initial stages of germination, the enzyme lipase acted rapidly. Increase of about $75 \%$ in the rate of enzyme action was recorded from phase change "I" to "R". ANOVA result revealed significant differences among all the phases of activities. During germination the Lipase activity didnt find to differ between the pahses "R" and "E" and " $\mathrm{H}$ " and "B" rest all the pahses were Statistically differed from each other

\section{Discussion :}

The rate of germination for any seed mainly depends on various physical and biological factors. In cases of various seeds having qualities to serve as a great source of nutrition, cannot be properly utilized because of their lower ability of germination and thus incapable of being convincing to be developed or cultivated by the growers for commercial purposes. Thus, the germination studies are important for determining the quality of the seeds for raising the crop or the respective plant. The Tamarindus indica L. seeds stored in poly bags at a temperature of $15^{\circ} \mathrm{C}$ showed $63 \%$ germination which was higher than those stored in room temperature (18\%). And the normally stored and germinated tamarind seeds showed very poor germination ability. Preliminary germination tests showed a very low percent of germination because the seeds exhibited dormancy. Ajiboye (2010), also conducted similar preliminary tests on randomly collected T. indica seeds and found a slightly higher percentage of germination up to day 5 . This difference in germination ability perhaps due to the differences in techniques used in both the experimemnts.

Starch degradation and its metabolism were studied extensively in many kinds of cereal and some legumes Bewley \& Black (1994). During germination of several species, amylase activity increases in the cotyledons and the starch content decreases (Prakash et al., 2015). There are two mechanisms for starch degradation; i) amyliticinvolving amylases, ii) the phosphorolytic- involving phosphorylase. The amylitic pathway is the major pathway for degradation of cotyledonary starch reserves in pea and similar legumes (Murtaza \& Asghar, 2012).
In case of Tamarindus indica L., the amylase activity increased up to the phase "E" (264hr of germination). Then increase of $14.2 \%$ was recorded from "B" to " $E$ ". This was the time of epicotyl extension. After this period, activity again declined slowly towards the next phase. The loss of activity was $9.8 \%$ from "E" to "L". It might be signifying that the amount of starch present per pair of cotyledons in the seed was much more. It was known that amylase activity was directly proportional to the starch content. So this condition encompassed within its span of rapid starch break down indicated its importance in the mobilization of starch reserves in the cotyledons. Amylase activity was found to be lower in cotyledons. Thus it represented that the amylase was the major pathway of starch degradation in the axis and not that much significant in cotyledons of germinating seeds. Bhushan \& Gupta (2008) reported similar results in oat seeds and demonstrated that during germination, amylases in the cotyledons increased rapidly from $4^{\text {th }}$ to $10^{\text {th }}$ day and then leveled off.

Increase in activities of proteases was correlated with the breakdown of storage proteins supported that these proteases were responsible for protein degradation Ramakrishna \& Rao (2004). Mobilization of storage protein in germinating seeds was initiated by endoproteases which converted the water-insoluble storage protein into soluble peptides that could be further hydrolyzed to amino acids by exopeptidases (Ramakrishna \& Rao, 2005). Protease activity of brown rice increased seven folds during 7 days of germination and showed the highest rate on day 6 when determined at $\mathrm{pH}$ 3.5 by Li et al. (2011), while in present study increament of protease activity was evidenced up to the $9^{\text {th }}$ day of germination. In Tamarind seeds, the rate of germination was very low due to a cover the intermediate phases by the cotyledons. The rate of protease activity was at its peak between " $\mathrm{H}$ " that was between $144 \mathrm{hr}$ to $216 \mathrm{hr}$ of germination. In our study the comparison of protease activity at all the six intermediate phases of germination showed slight difference in the rate of protease activity from that of Indian bean. Similar results were obtained by Prisco (2006) in azocaseinase proteolytic activity in Vigna sinensis cotyledons. Increase in protease activity was observed up to $9^{\text {th }}$ day of sowing and then rapid loss in activity was recorded up to $15^{\text {th }}$ day. Investigations made by Akhtaruzzaman et al. (2012) on protease activity in seven leguminous seeds, soybean, lentil, black gram, green gram, Bengal gram, groundnut and pea bean revealed almost the similar results.

Lipase enzyme breaks down or degrades the complex insoluble lipids into simpler fatty acids and alcohol which can be easily carried to the point of axis growth and become utilized by it. Some seeds germinate faster than others due to more lipid accumulation and further mobilization of it. These seeds germinate faster due to 
higher lipase activity in degrading the stored lipid in the cotyledons, while others give a poor response (Cantisen et al., 1999) Possibly it is due to the slower utilization of reserve lipids by the embryo for its growth during seed germination. The proper utilization of lipid by the embryo is solely dependent on one of the major hydrolases responsible for its degradation and that is lipase. In our study the lipid change and the mode of lipase activity in revealed similar results as obtained by Munshi et al. (2007) and Nahak et al. (2010). A very high rate of lipid degradation was observed at the initial phases of germination in the seeds. An increase in lipase activity between the phases "I" and "R" was recorded as $75 \%$ in case of tamarind cotyledons. This increase in activity continued up to the phase "B" that was after $216 \mathrm{hr}$ of germination. The increase in lipase activity for a longer period in the seed was due to its higher content of lipid and slower rate of germination. The maximum rate of activity was observed from a change of phase "I" to "R". This was because of the insoluble lipids, especially fats started breaking down after imbibition which resulted in the swelling of the seed, breaking off the seed coats and resulting radicle expansion or emergence. This entire phenomenon required most of the reserve nutritional energy and in order to satisfy the need of the growing seedling.

Lipases showed their highest activity during the initial period of germination. The rate of germination was directly proportional to the lipid content and its mobilization and this relation were seen earlier in the seedlings of sunflower (Bahri, 200o). A higher amount of lipid was observed in the embryonic axes of fast-growing seeds of sunflower on the $8^{\text {th }}$ and $10^{\text {th }}$ day of germination. It was due to enhanced fatty acid synthesis and due to lipase activity. Nguyen et.al. (2016) emphasized that germinating seeds synthesized fatty acids from lipids (fats) by the enzyme lipase which was used in the formation of membrane lipids in the growing embryos. Thus an increase in lipid content was seen in the axis of seedlings during germination observed by Munshi et al. (2007). Similar observations were made by Gadge, et al. (2011) in oil seeds of Glycine max. While seven other oilseeds from seven different species namely, castor bean, peanut, sunflower, cucumber, cotton, corn, and tomato. The storage tissues of all these oilseeds except castor bean contained only alkaline lipase activity which increased drastically during germination, confirmed Sana et.al. (2004).

Study on hydrolases and their activities expressed the role of such enzymes in the utilization of cotyledonary content in germination and seedling development in the seeds. Amylosis was the major pathway of starch hydrolysis. Very little amylase activity persisted in the early stages of germination. So most of the amylase was synthesized de novo in the cotyledons. Amylase activity increased for a longer period in germinating cotyledons of Tamarindus indica L. due to their slower rate of starch degradation. Mobilization of storage protein in leguminous seeds represented one of the most important post-germinative events in the growth and development of seedling. Proteolytic enzymes, mostly proteases played the central role in mobilization and utilization of reserve protein. Complex protein hydrolysis into simpler and soluble peptides was faster in the early stages of germination and became slower afterwards in later phases. Maximum activity occurred between the phases of hypocotyls extension ("H") and branching in radicle ("B") as this was physiologically the most active period of germination. Utilization of stored lipids especially fats in the leguminous seeds was monitored by estimation of lipase activity. The enzyme got activated as soon as water became available to the inner contents of the seed by imbibition. These facts regarding change in hydrolytic enzymes during seed germination would be helpful in developing new technologies to improve germination percentage of tamarind and similar seeds.

\section{Acknowledgements:}

First author is thankful to the Principal, Govt. Nagarjuna P.G. College of Science, Raipur, C.G. for his support and positive inspiration. Thanks are also due for the Principal, Ravenshaw University, Cuttack, Odisha for his kind support as a portion of this study was conducted there.

\section{References:}

Ajiboye, A.A. (2010): Dormancy and seed germination in Tamarindus indica L. Pac. J. Sci. Technol., 11(2):463-470..

Akhtaruzzaman, M., Mozumder, N.H.M.R., Jamal, R., Rahman, A. \& Rahman, T. (2012): Isolation and characterization of protease enzyme from leguminous seeds. Agri. Sci. Res. J., 2(8):434-440.

Arunachalam, C. \& Saritha, K. (2009): Protease enzyme: an ecofriendly alternative for leather industry. Indian J. Sci. Technol., 2(12):29-32.

Bahri, S. (2000): Lipase activity in germinating sunflower seedlings. Biochem. Soc. Trans.,28(6):771-773.

Bewley, J.D. \& Black,M. (1994): Seeds: Physiology of development and germination. Pub. by: Plenum Press, New York, USA. 445p.

Bhushan, B. \& Gupta, K. (2008) Effect of lead on carbohydrate mobilization in oat seeds during germination. J. Appl. Sci. Environ. Manage., 12(2):29-33.

Botcha, S., Prattipati, S. \& Atluru, A. (2011): Biochemical changes during seed germination of Sterculia urens Roxb. Not. Sci. Biol.,3(3):105-108.

Cantisen, S., Force, E.M., Ortega, R.A. \& Garces, R. (1999): Lipid characterization in vegetable tissues of high saturated fatty acid sunflower mutants. L. Agri. Food Chem., 47:78-82.

Gadge, P.P., Madhikar, S.D., Yewle, J.N., Jadhav, U.U., Chougale, A.D., Zambare, V.P. \& Padul, M.V. (2011): Biochemical studies of lipase from germinating oil seeds (Glycine max). Am. J. 
Biochem. Biotechnol., 7(3):141-145.

Gorecki, R.J., Fordonski, G., Halmajan, H., Horbowicz, M., Jones, R.G. \& Lahuta, L.B. (200o) Seed physiology and biochemistry, 138-143 pp. In, Hedley, C.L. (eds.) Carbohydrates in grain legume seeds, seed Physiology and Biochemistry. CABebook, Oxon.

Li, C., Cao, X., Gu, Z. \& Wen, H. (2011) A preliminary study of the protease activities in germinating brown rice (Oryza sativa L.). L.Sci. Food Agric., 91(5):915-920..

Misra, N.M. \& Kar, R.K. (2002): Effect of light, gibberellic acid and kinetin on amylase formation in cotyledons of germinating cowpea. Geobios, (2-3): 29:125-128. .

Munshi, S.K., Sandhu, S. and Sharma, S. (2007) Lipid composition in fast and slow germinating sunflower (Helianthus annus L.) seeds.J. Gen. Appl. Plant Physiol., 33(3-4):235-246.

Murtaza,G. \& Asghar, R. (2012): $\alpha$-Amylase activities during seed development and germination in pea treated with salicylic acid. Pak. J. Bot., 44(6): 1823-1829.

Nahak, G., Mohanty, C.K., Mohapatra, N.K. \& Sahu, R.K. (2010) Enzymatic transesterification of lipases obtained from bacterial and plant sources. Conti.J. Biomed. Sci., 4:21-36..

Nigam, A. and Ayyagari, A. (2007): Lab Mannual of Biochemistry, Immunology and Biotechnology. Pub. by: Tata McGraw Hill, New Delhi. 358 p.

Nguyen, Q.T., Kisiala, A. \& Narine, S. (2016): Seed development : Fatty acids and phytohormone metabolism and their interactions. Curr. Genomics, 17(3):241-260.

Oboh, G. (2005): Isolation and characterization of amylase from fermented cassava (Manihot esculenta Crantz.) waste water. Af. J. Biotech., 4(10):1117-1123.

Padmakar, B., Madhavilatha, P. \& Ramakrishna, V. (2005): Purification of Alkaline Protease from the Cotyledons of Germinating Indian Bean (Dolichos lablab L. var lignosus) Seeds. Biotechnology, 4(4):365-369.

Prakash, S., Sharma, S. \& Yadav, K. \& Yadav, R. (2015): Biochemical Analysis of Amylases During Germination of Buckwheat (Fagopyrum esculentum) Seeds: A Pharmaceutical Plant. Int. J. Sci. Res. Methodol., 2(1):31-46.

Prisco, J.T., Ainouz, I.L. \& Melo, S. deC. (2006) Changes in nitrogenous compounds and proteases during germination of Vigna sinensis seeds. Physiologia Plantarum, 33(1):18-21.

Plummer, D.T. (2011): An Introduction to Practical Biochemistry. Pub. by: Tata McGraw Hill Edition, New Delhi. 318 p.

Ramakrishna, V. \& Rao, R.P. (2004): Storage protein degradation in germinating Indian bean (Dolichos lablab L. var. lignosus) seeds. Seed Sci. Technol., 34(1):161-168.

Ramakrishna, V. \& Rao, R.P. (2005): Purif ication of acidic protease from the cotyledons of germinating Indian bean (Dolichos lablab L. var lignosus) seeds. Af. J. Biotechnol., 4(7): 703-707.

Sana, N.K., Hossin, I., Haque, E.M. \& Shaha, R.K. (2004): Identification, Purif ication and Characterization of Lipase from Germinating Oil Seeds (Brassica napus L.). Pak. J. Biol. Sci., $7(2): 246-252$.

Schmidt, L.H. (2000): Guide to Handling of Tropical and Subtropical Forest Seed. Pub. by: Danida Forest Seed Centre. $532 \mathrm{p}$. 